Supplement of The Cryosphere, 15, 2647-2665, 2021 https://doi.org/10.5194/tc-15-2647-2021-supplement (c) Author(s) 2021. CC BY 4.0 License.

(c) (i)

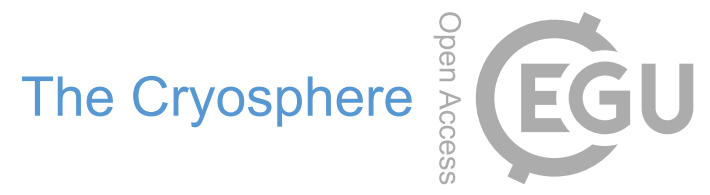

Supplement of

\title{
Mechanics and dynamics of pinning points on the Shirase Coast, West Antarctica
}

\author{
Holly Still and Christina Hulbe \\ Correspondence to: Holly Still (holly.still@otago.ac.nz)
}

The copyright of individual parts of the supplement might differ from the article licence. 


\section{Model set-up and comparison between observations and model output}

\subsection{Physical constants}

Table S1. Physical constants used in the Ice-sheet and Sea-level System Model (ISSM).

\begin{tabular}{lll}
\hline Gravitational acceleration & $g$ & $9.81 \mathrm{~m} \mathrm{~s}^{-2}$ \\
Density of ice & $\rho_{\mathrm{i}}$ & $917 \mathrm{~kg} \mathrm{~m}^{-3}$ \\
Density of seawater & $\rho_{\mathrm{sw}}$ & $1023 \mathrm{~kg} \mathrm{~m}^{-3}$ \\
Density of freshwater & $\rho_{\mathrm{w}}$ & $1000 \mathrm{~kg} \mathrm{~m}^{-3}$ \\
Mixed layer specific heat capacity & $c_{\mathrm{p}}$ & $3974 \mathrm{~J} \mathrm{~kg}^{-1} \mathrm{~K}^{-1}$ \\
Thermal exchange velocity & $\gamma$ & $1 \times 10^{-4} \mathrm{~m} \mathrm{~s}^{-1}$ \\
Latent heat capacity of ice & $L_{\mathrm{i}}$ & $3.35 \times 10^{5} \mathrm{~J} \mathrm{~kg}^{-1}$ \\
Glen's flow law exponent & $n$ & 3 \\
\hline
\end{tabular}

\subsection{Improvements to the model representation of pinning points}

Some minor adjustments are made to model boundaries before relaxation. The friction coefficient assigned to Crary Ice Rise

5 and Steershead Ice Rise is increased to $\infty$ to ensure zero velocity, characteristic of ice rises. Model bathymetry beneath the Ross Ice Shelf (RIS) is adjusted to prevent the formation of new ice rumples during relaxation. This adjustment is necessary because the Bedmap2 sub-ice shelf bathymetry used to create the model geometry is interpolated from limited resolution (55 km) point measurements onto a $1 \mathrm{~km}$ grid (Fretwell et al., 2013). Predictably, the depth of the water column beneath the RIS is incorrect in some areas and this poses particular problems where the seafloor is unrealistically shallow. Water column depths of less than $50 \mathrm{~m}$ near the Shirase Coast Ice Rumples (SCIR) and Steershead Ice Rise (SIR) result in spurious grounding and the formation of new ice rumples, as well an increase in the area of existing pinning points.

Unrealistic grounding is prevented by excavating a $500 \mathrm{~m}$ thick layer from the bed elevation beneath the RIS (Fig. S1). The bathymetry within $30 \mathrm{~km}$ of the MacAyeal Ice Stream (MacIS), Bindschadler Ice Stream (BIS) and Whillans Ice Stream grounding line is left unmodified to allow for grounding line adjustment during model relaxation and transient simulations. The bed elevation of existing pinning points is left unmodified while the surrounding bathymetry is excavated to ensure the area of grounding represents the present-day extent of the pinning points. Smooth transitions between unmodified and excavated bed elevations are achieved by linearly interpolating within a 2 to $5 \mathrm{~km}$ buffer marking the transition between unmodified and excavated bed elevations. This approach is inspired by Fürst et al. (2015) and Favier et al. (2016) who also noted inconsistencies in the Bedmap2 bathymetry that resulted in spurious regrounding when simulating ice shelf flow over pinning points.

The friction coefficient initially inferred for the SCIR (described in Section 2.2) is adjusted to achieve a more realistic ice rumple area and geometry, and to better represent the basal drag inferred by Still et al. (2019). The inversion results in excessively large friction coefficient values (corresponding to $\tau_{\mathrm{b}}>400 \mathrm{kPa}$ ) inferred for mesh elements on the upstream side of the SCIR complex, and zero values inferred for downstream ice rumple elements (Fig. S2). Landsat 8 imagery indicates that 


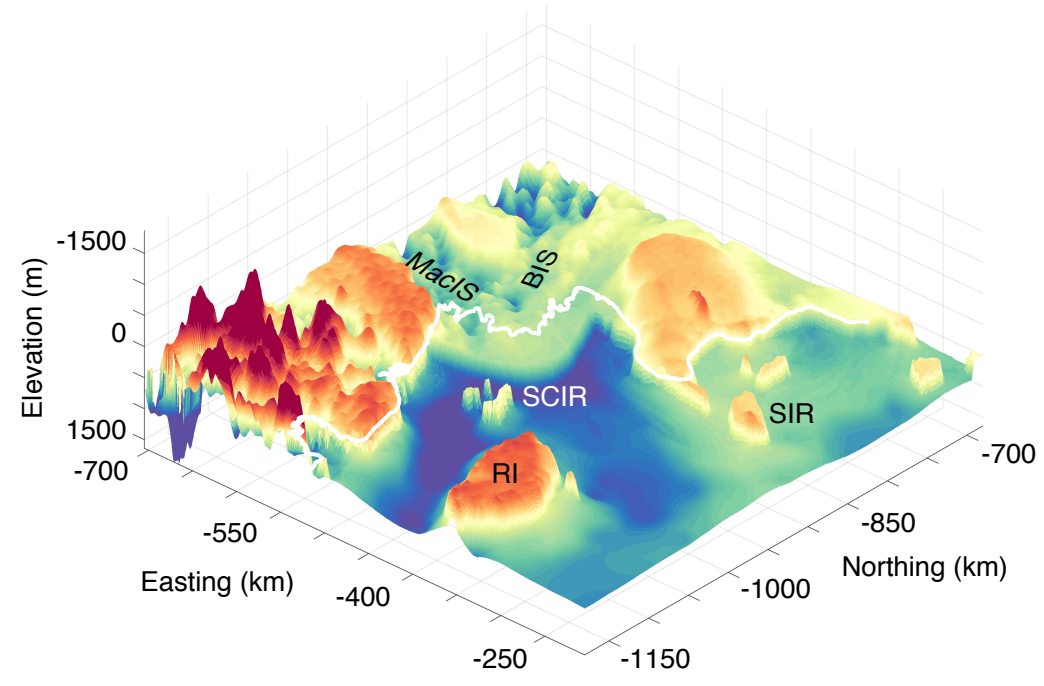

Figure S1. The modified Bedmap2 bathymetry around the SCIR. The white line indicates the location of the present-day grounding line (Bindschadler et al., 2011).

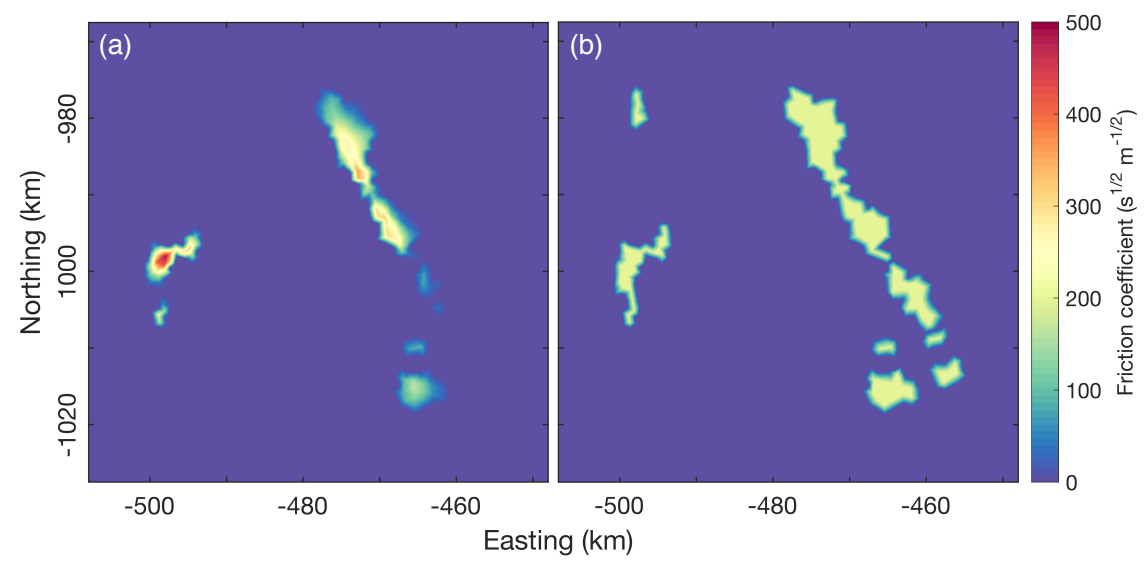

Figure S2. A comparison between (a) the original friction coefficient inferred for the SCIR model nodes using an inverse method and (b) the friction coefficient after manual adjustment. 
Table S2. Performance of the inverse method to infer the inverse rate factor $\bar{B}_{\text {inv }}$ and the friction coefficient $\alpha$. The mean absolute error (MAE) and the root mean square error (RMSE) indicate the agreement between modelled and observed ice velocity.

\begin{tabular}{lccc}
\hline & Inferred parameter & $\operatorname{MAE}\left(\mathrm{m} \mathrm{a}^{-1}\right)$ & $\mathrm{RMSE}\left(\mathrm{m} \mathrm{a}^{-1}\right)$ \\
\hline \multirow{2}{*}{ Ice shelf } & $\bar{B}_{\text {inv }}$ & 7.4 & 11.3 \\
\multirow{3}{*}{ Entire domain } & $\alpha$ & 7.9 & 11.8 \\
& $\bar{B}_{\text {inv }}$ & 5.2 & 7.8 \\
& $\alpha$ & 13.3 & 15.3 \\
\hline
\end{tabular}

this representation is incorrect. Downstream rumples provide basal drag and generate surface relief comparable to the upstream rumples in the complex (implying that basal drag is greater than zero).

To examine sensitivity to basal friction, a range of different friction coefficient values $\left(\alpha=0\right.$ to $\left.800 \mathrm{~s}^{1 / 2} \mathrm{~m}^{-1 / 2}\right)$ were assigned to the ice rumple nodes before model relaxation. A friction coefficient value that reproduces a relaxed model geometry close to present-day ice velocity and thickness, and that produces a basal drag magnitude similar to the basal drag inferred in a force budget analysis (Still et al., 2019), is used in the model experiments (i.e. $\alpha=200 \mathrm{~s}^{1 / 2} \mathrm{~m}^{-1 / 2}$ ). The manual adjustment ensured that all of the individual ice rumples in the complex (and the associated velocity gradients and resistive stresses) were represented appropriately.

\subsection{Performance of the inverse method}

Reference model velocities are well matched to observed velocities (Table S2, Fig. S3). For both $\bar{B}$ and $\alpha$, the mean absolute error between modelled and observed ice velocity is less than the error on the observed Landsat 8-derived and MEaSUREs velocities used in model initialisation. The agreement between modelled and observed velocity compares well to reported mean absolute errors for similar inversions performed with ISSM (Morlighem et al., 2010; Yu et al., 2018). 
(a) Inverse rate parameter $\left(\times 10^{8} \mathrm{~Pa} \mathrm{~s}^{1 / 3}\right)$

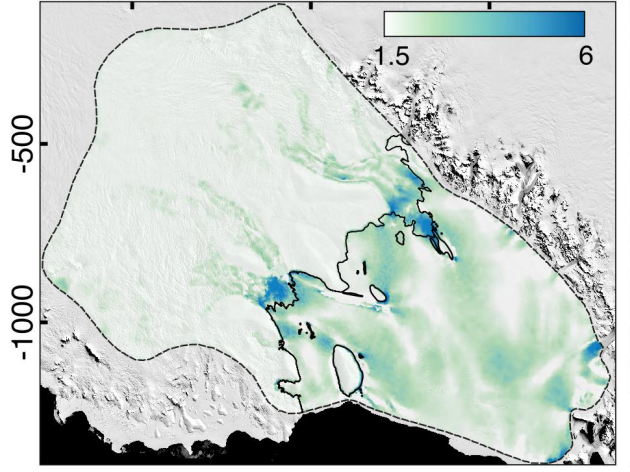

(c) Friction coefficient $\left(\mathrm{s}^{1 / 2} \mathrm{~m}^{-1 / 2}\right)$

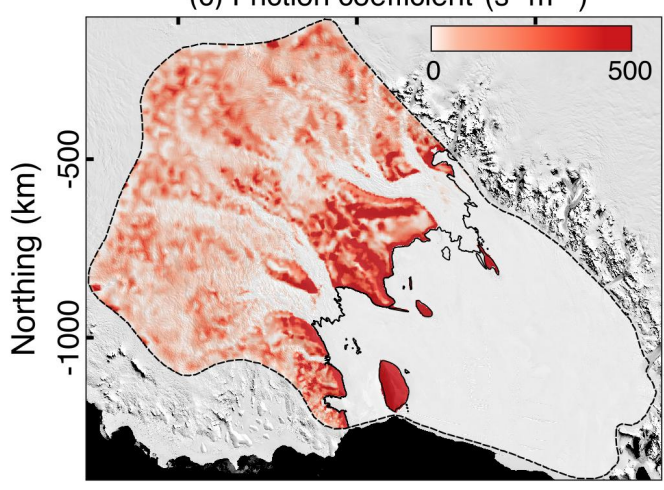

(e) Observed velocity (ma-1)

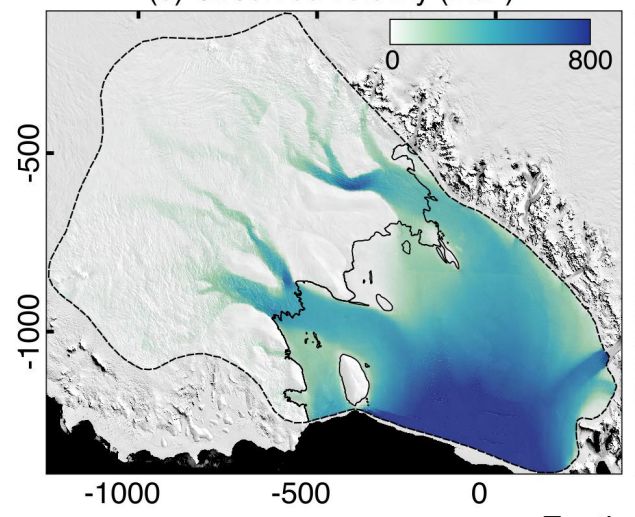

(b) Velocity difference $\left(\mathrm{ma}^{-1}\right)$

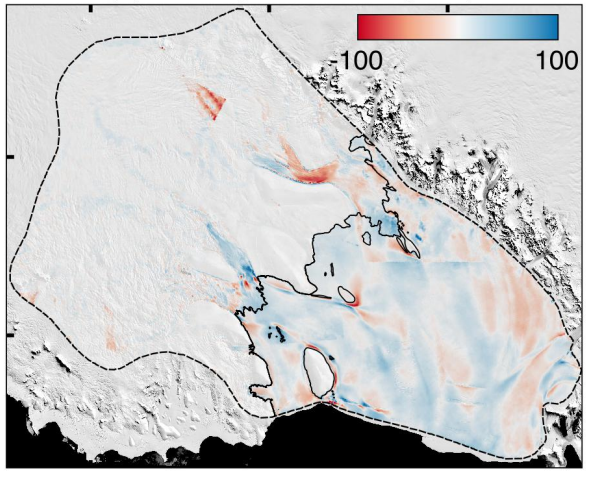

(d) Velocity difference $\left(\mathrm{ma}^{-1}\right)$

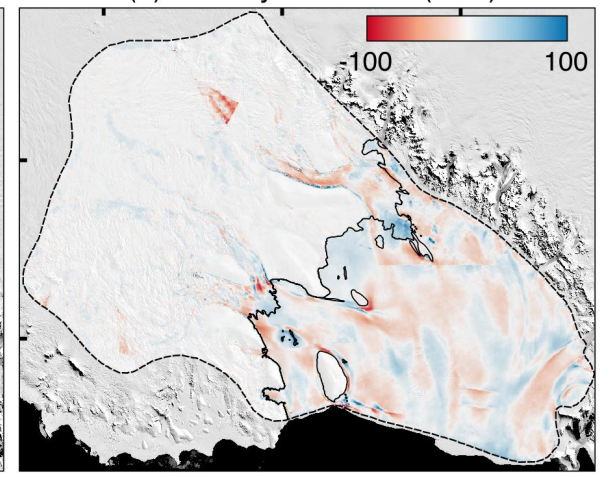

(f) Modelled velocity $\left(\mathrm{ma}^{-1}\right)$

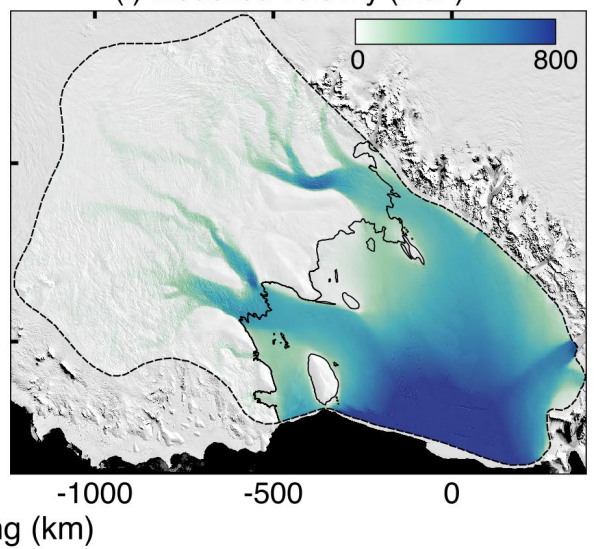

Figure S3. Model output from the final two inversions to infer the inverse rate parameter $\bar{B}_{\text {inv }}$ and basal friction coefficient $\alpha$. Panel (a) is the inferred distribution of $\bar{B}_{\text {inv }}$, (b) is the difference between modelled and observed velocity corresponding to the $\bar{B}_{\text {inv }}$ inversion, (c) is the inferred distribution of $\alpha$ and (d) is the velocity difference corresponding to the $\alpha$ inversion. Panels (e) and (f) are a comparison between the observed and final modelled velocity for inferred $\alpha$. Model output is overlayed on the MODIS MOA (Haran et al., 2014). 

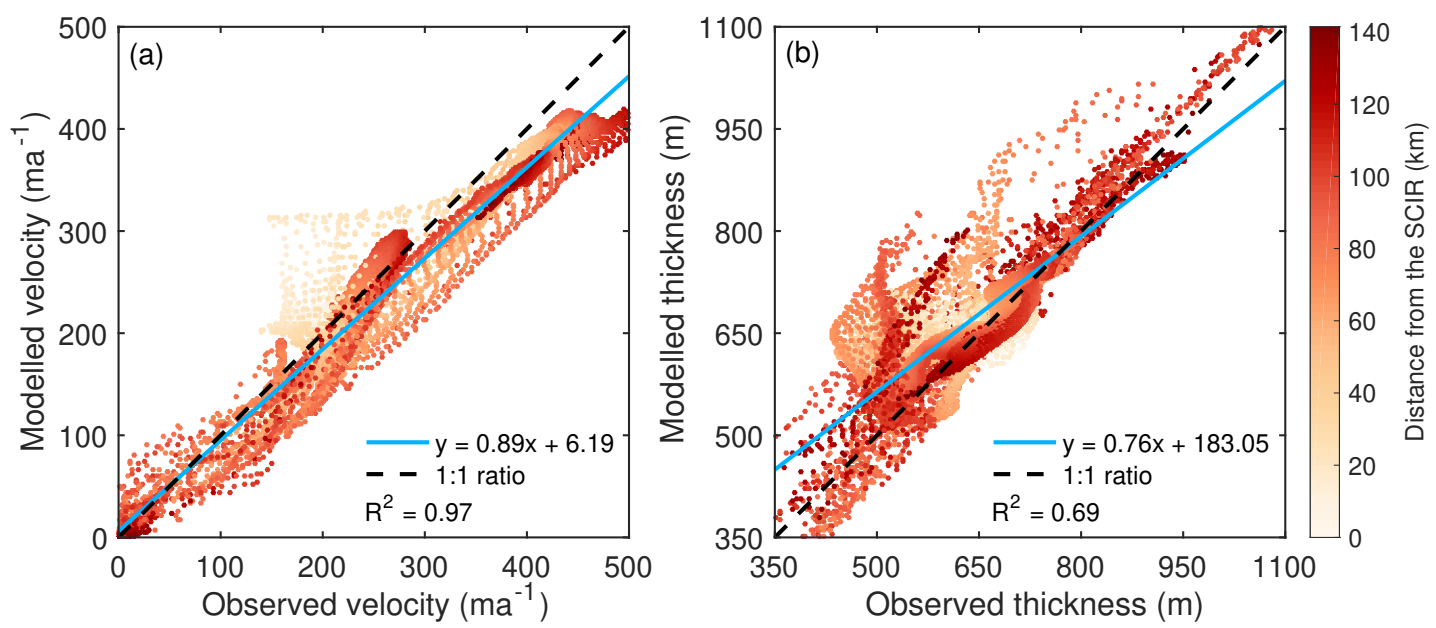

Figure S4. The relationship between (a) modelled and observed ice velocity (Landsat 8) and (b) modelled and observed ice thickness (Bedmap2) after model relaxation for the $\bar{B}_{\text {inv }}$ case. $n=10201$ points sampled at a $2 \mathrm{~km}$ resolution within a $200 \times 200 \mathrm{~km}$ grid centred on the SCIR.

\subsection{Comparison between modelled and observed ice velocity and thickness after model relaxation}

Fine-scale spatial variations in ice velocity and flowline turning around the SCIR are replicated by the model (Figs. S3f and S4a), but finer kilometre-scale variations in ice thickness are not (Figs. S4b and S5). Model velocity retains fine spatial detail because it depends on the inverse rate factor and the friction coefficient, both of which are spatially fixed properties of the model mesh elements. Lacking such constraint, the thickness field is smoothed by viscous diffusion during model relaxation. While the broad pattern of thickening upstream and thinning downstream of the SCIR is preserved, kilometre-scale features including wakes of thinner ice downstream from individual ice rumples are not reproduced (Fig. S5).

A realistic assessment of the flow-regulating effects of the SCIR requires a model ice-shelf thickness above buoyancy $H_{\mathrm{ab}}$ that is consistent with the observed $H_{\mathrm{ab}}$ from the Bedmap2 compilation. If the model $H_{\mathrm{ab}}$ is too high, the flow-regulating effects of the pinning points will be exaggerated, while if $H_{\mathrm{ab}}$ is too low (ice rumples are too lightly grounded), the flowregulating effects will be underestimated. After model relaxation, $H_{\mathrm{ab}}$ ranges from $-6 \mathrm{~m}$ to $23 \mathrm{~m}$ with a mean $H_{\mathrm{ab}}$ of $13 \mathrm{~m}$ (Fig. S5c and d). Negative $H_{\mathrm{ab}}$ values indicate that some initially grounded ice rumple nodes lost contact with the seafloor during model relaxation (e.g. the downstream western corner of rumple C). 


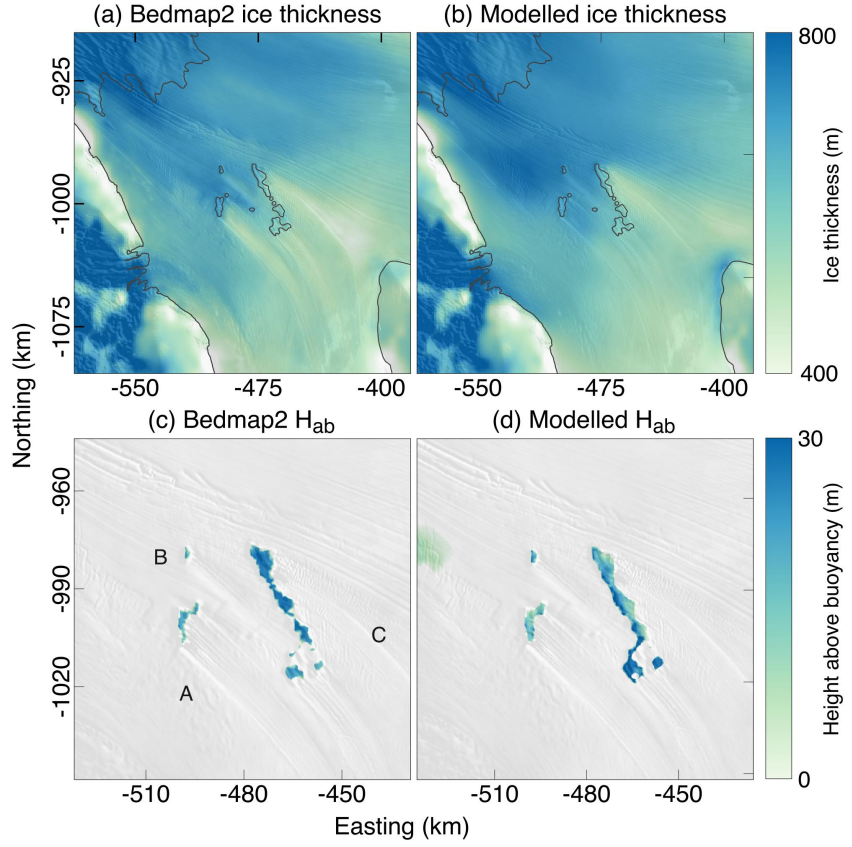

Figure S5. Panels (a) and (b) show a comparison between Bedmap2 (Fretwell et al., 2013) and modelled ice thickness near the SCIR. Panels (c) and (d) show a comparison between Bedmap2-derived and modelled ice-shelf height above buoyancy $H_{\mathrm{ab}}$ (degree of groundedness). $H_{\mathrm{ab}}$ indicates the amount of thinning required for the ice shelf to lose contact with the seafloor. Zero values indicate floating ice. Model output is from the $\bar{B}_{\text {inv }}$ reference model and overlayed on the MODIS MOA (Haran et al., 2014).

\section{$50 \quad 2$ Transverse stresses}

Longitudinal tensile and compressive stresses in the across-flow direction are referred to as transverse stresses $\bar{R}_{t t}$. Positive and negative $\bar{R}_{t t}$ (indicating flow divergence and convergence) are plotted separately for clarity (Fig. S6 and S7). 

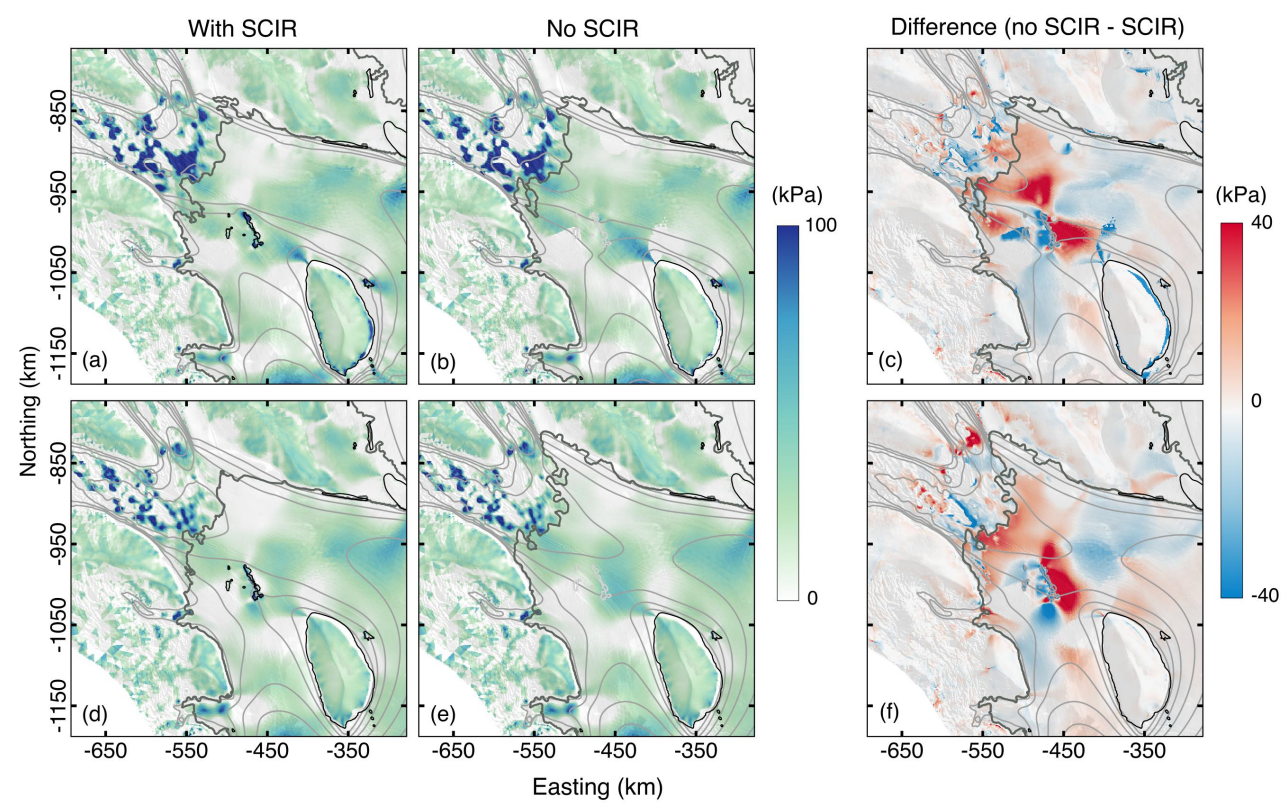

Figure S6. The transverse stress $+\bar{R}_{t t}$ (flow divergence) acting on the RIS and tributary ice streams with and without the SCIR. In panels (a)-(c), the model is initialised with $\bar{B}_{\text {inv }}$. In panels (d)-(f), the model is initialised with $\bar{B}_{\mathrm{u}}$. In panels (c) and (f), positive (negative) values indicate an increase (decrease) in flow divergence when the SCIR are removed.
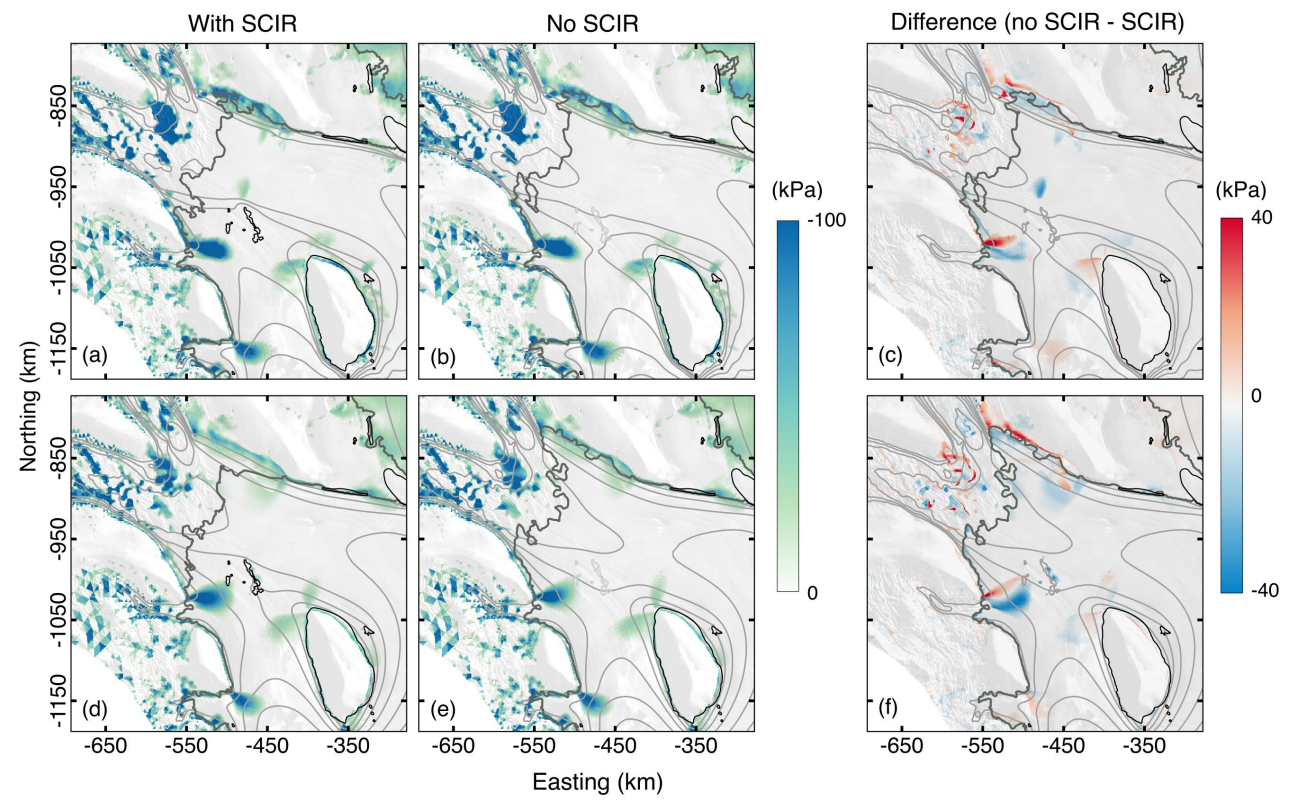

Figure S7. The transverse stress $-\bar{R}_{t t}$ (flow convergence) acting on the RIS and tributary ice streams with and without the SCIR. In panels (a)-(c), the simulation is initialised with $\bar{B}_{\text {inv }}$. In panels (d)-(f), the simulation is initialised with $\bar{B}_{\mathrm{u}}$. In panels (c) and (f), positive (negative) values indicate an increase (decrease) in flow convergence when the SCIR are removed. 


\section{The force budget}

The pinning point force budget quantifies the magnitude and direction of drag forces and net flow resistance generated by individual pinning points (MacAyeal et al., 1987; Still et al., 2019). Form drag $\boldsymbol{F}_{\mathrm{f}}$ is the glaciostatic contribution to the net flow resistance associated with disturbance to the thickness field around an obstacle and is calculated on a contour $\Gamma$ surrounding the pinning point

$\boldsymbol{F}_{\mathrm{f}}=\oint_{\Gamma}\left\{\frac{1}{2} \rho_{i} g H^{2}\right\} \hat{\boldsymbol{n}} \mathrm{d} \lambda$

where $\rho_{\mathrm{i}}$ is the density of ice, $g$ is acceleration due to gravity and $H$ is the ice thickness. The contour $\Gamma$ is divided into length elements $\mathrm{d} \lambda$ with normals $\hat{\boldsymbol{n}}$. Equation (1) differs slightly from the $\boldsymbol{F}_{\mathrm{f}}$ equation used by MacAyeal et al. (1987) because the total ISSM ice-column thickness $H$, in which a firn layer is not represented separately, is used here.

Dynamic drag $\boldsymbol{F}_{\mathrm{d}}$ is the viscous resistance associated with deformation around an obstacle and is calculated

$\boldsymbol{F}_{\mathrm{d}}=-\oint_{\Gamma} 2 \bar{\eta} H\left\{\dot{\boldsymbol{\epsilon}}_{i j} \cdot \hat{\boldsymbol{n}}+\left(\dot{\epsilon}_{x x}+\dot{\epsilon}_{y y}\right) \hat{\boldsymbol{n}}\right\} \mathrm{d} \lambda$

where $\bar{\eta}$ is the effective depth-averaged viscosity and $\dot{\boldsymbol{\epsilon}}_{i j}$ is the strain rate tensor. The effective viscosity parameter $\bar{\eta}$ is

$65 \bar{\eta}=\frac{\bar{B}}{2 \dot{\epsilon}_{\mathrm{e}}^{1-1 / n}}$

where $\bar{B}$ is the depth-averaged, inverse flow law rate factor and $n=3$ is the flow law exponent. The effective strain rate $\dot{\epsilon}_{\mathrm{e}}$ is the second invariant of the strain rate tensor

$\dot{\epsilon}_{e}^{2}=\frac{1}{2}\left(\dot{\epsilon}_{x x}^{2}+\dot{\epsilon}_{y y}^{2}+\dot{\epsilon}_{z z}^{2}\right)+\dot{\epsilon}_{x y}^{2}+\dot{\epsilon}_{x z}^{2}+\dot{\epsilon}_{y z}^{2}$.

The difference between the sum of the form drag and dynamic drag $\left(\boldsymbol{F}_{\mathrm{f}}+\boldsymbol{F}_{\mathrm{d}}\right)$ and the resistive force that would exist in the absence of any disturbance to ice shelf flow (the seawater pressure), is the effective resistance $\boldsymbol{F}_{\mathrm{e}}$, the total reaction force arising from contact between the pinning point and the ice shelf base

$\boldsymbol{F}_{\mathrm{e}}=\boldsymbol{F}_{\mathrm{f}}+\boldsymbol{F}_{\mathrm{d}}-\boldsymbol{F}_{\mathrm{w}}$

where $\boldsymbol{F}_{\mathrm{w}}$ is the seawater pressure. The force budget components are computed for the SCIR and Roosevelt Island using both $\bar{B}_{\text {inv }}$ and $\bar{B}_{\mathrm{u}}$ for the reference and perturbed models.

\subsection{Roosevelt Island force budget}

Modelled net resistive forces generated by Roosevelt Island increase in magnitude in response to removal of the SCIR. $\boldsymbol{F}_{\mathrm{f}}$ increases by $5 \%, \boldsymbol{F}_{\mathrm{d}}$ increases by $6 \%$ and $\boldsymbol{F}_{\mathrm{e}}$ increases by $6 \%\left(\boldsymbol{F}_{\mathrm{e}}=37.8 \times 10^{12} \mathrm{~N}\right.$ with SCIR, $\boldsymbol{F}_{\mathrm{e}}=40.0 \times 10^{12} \mathrm{~N}$ without SCIR) (Table 3). The directions of net $\boldsymbol{F}_{\mathrm{f}}, \boldsymbol{F}_{\mathrm{d}}$ and $\boldsymbol{F}_{\mathrm{e}}$ remain unchanged (Fig. S9). Once the SCIR are removed, $\boldsymbol{F}_{\mathrm{e}}$ generated at the location of the former SCIR reduces to near-zero and $\boldsymbol{F}_{\mathrm{e}}$ generated by Roosevelt Island increases to balance the driving force. This result is consistent with the analysis of resistive stress distributions. In particular, lateral shear stresses $\bar{R}_{l t}$ and longitudinal compressive stresses $-\bar{R}_{l l}$ generated by Roosevelt Island increase in response to removal of the SCIR. 


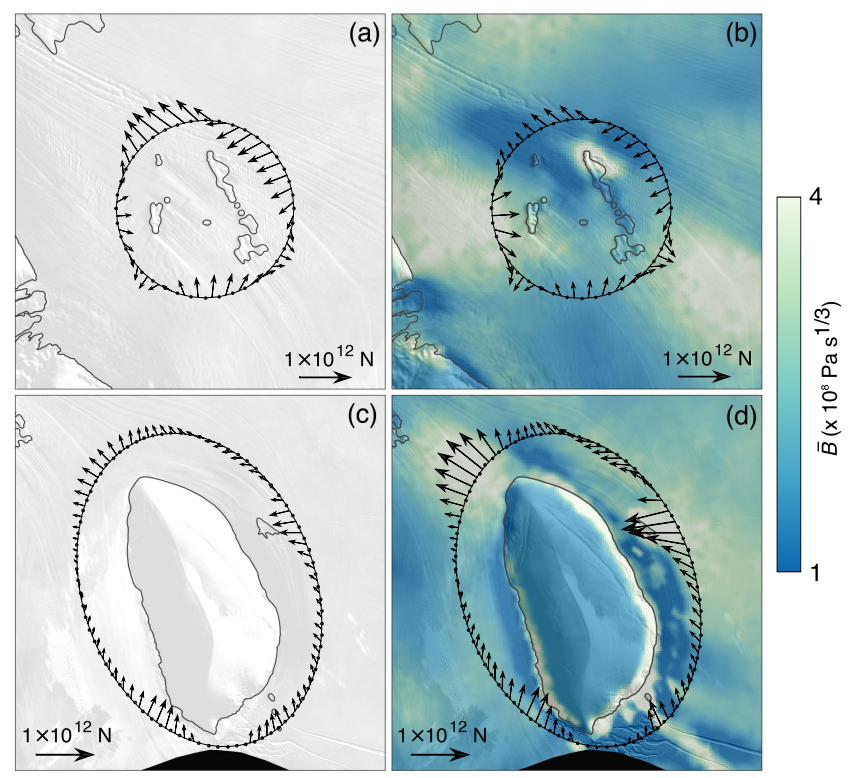

Figure S8. The effect of uniform $\bar{B}_{\mathrm{u}}(\mathbf{a}, \mathbf{c})$ versus spatially variable $\bar{B}_{\text {inv }}(\mathbf{b}, \mathbf{d})$ on individual $\boldsymbol{F}_{\mathrm{d}}$ vector components generated by the SCIR and Roosevelt Island. Uniform $\bar{B}_{\mathrm{u}}$ is set to $2.2 \times 10^{8} \mathrm{~Pa} \mathrm{~s}^{1 / 3}$.

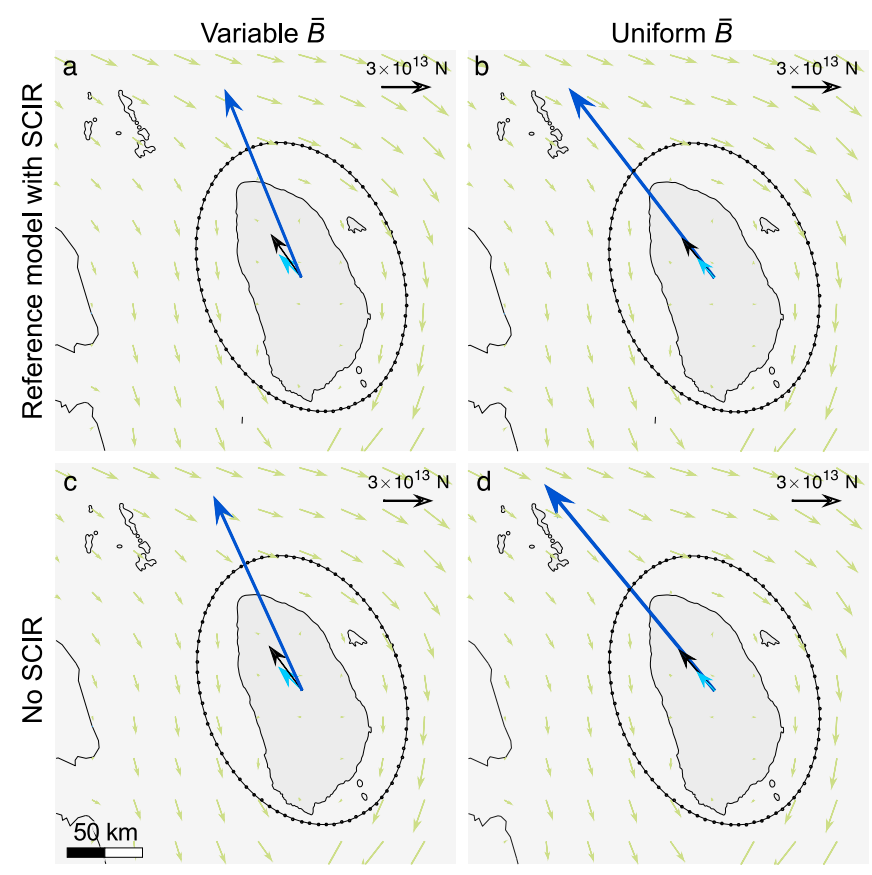

Figure S9. The change in net $\boldsymbol{F}_{\mathrm{f}}$ (dark blue), net $\boldsymbol{F}_{\mathrm{d}}$ (light blue) and $\boldsymbol{F}_{\mathrm{e}}$ (black) generated by Roosevelt Island in response to removal of the SCIR. The green ice velocity vectors indicate the flow direction. 
3.2 Differing responses of MacAyeal and Bindschadler ice streams to removal of the SCIR
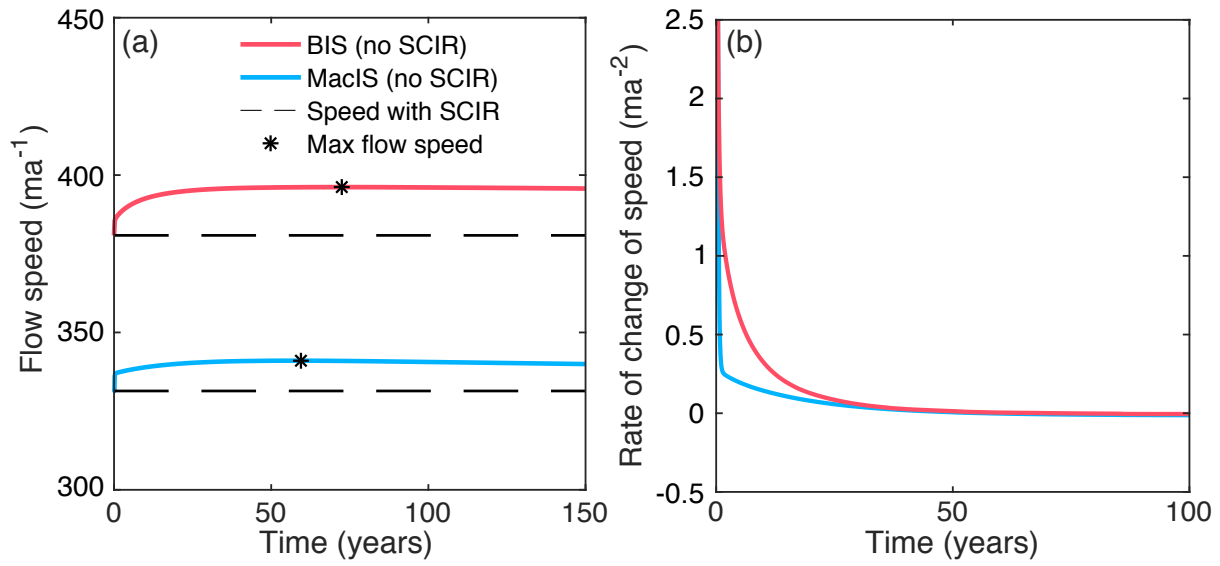

Figure S10. Comparison between the responses of MacIS and BIS to removal of the SCIR ( $\bar{B}_{\text {inv }}$ case). Panel (a) shows the ice stream flow speeds computed as spatial averages across the main ice stream trunks. Panel (b) shows the change in flow speed computed at each timestep. The 'time' variable refers to the number of years after removal of the SCIR from the model domain. 


\section{References}

Bindschadler, R., Choi, H., Wichlacz, A., Bingham, R., Bohlander, J., Brunt, K., Corr, H., Drews, R., Fricker, H., Hall, M., Hindmarsh, R., and Kohler, J.: Getting around Antarctica: new high-resolution mappings of the grounded and freely-floating boundaries of the Antarctic ice sheet created for the International Polar Year, The Cryosphere, 5, 569-588, https://doi.org/10.5194/tc-5-569-2011, 2011.

Favier, L., Pattyn, F., Berger, S., and Drews, R.: Dynamic influence of pinning points on marine ice-sheet stability: a numerical study in Dronning Maud Land, East Antarctica, The Cryosphere, 10, 2623-2635, https://doi.org/10.5194/tc-10-2623-2016, 2016.

Fretwell, P., Pritchard, H. D., Vaughan, D. G., Bamber, J. L., Barrand, N. E., Bell, R., Bianchi, C., Bingham, R. G., Blankenship, D. D., Casassa, G., Catania, G., Callens, D., Conway, H., Cook, A. J., Corr, H. F. J., Damaske, D., Damm, V., Ferraccioli, F., Forsberg, R., Fujita, S., Gim, Y., Gogineni, P., Griggs, J. A., Hindmarsh, R. C. A., Holmlund, P., Holt, J. W., Jacobel, R. W., Jenkins, A., Jokat, W., Jordan, T., King, E. C., Kohler, J., Krabill, W., Riger-Kusk, M., Langley, K. A., Leitchenkov, G., Leuschen, C., Luyendyk, B. P., Matsuoka, K., Mouginot, J., Nitsche, F. O., Nogi, Y., Nost, O. A., Popov, S. V., Rignot, E., Rippin, D. M., Rivera, A., Roberts, J., Ross, N., Siegert, M. J., Smith, A. M., Steinhage, D., Studinger, M., Sun, B., Tinto, B. K., Welch, B. C., Wilson, D., Young, D. A., Xiangbin, C., and Zirizzotti, A.: Bedmap2: improved ice bed, surface and thickness datasets for Antarctica, The Cryosphere, 7, 375-393, https://doi.org/10.5194/tc-7375-2013, 2013.

Fürst, J. J., Durand, G., Gillet-Chaulet, F., Merino, N., Tavard, L., Mouginot, J., Gourmelen, N., and Gagliardini, O.: Assimilation of Antarctic velocity observations provides evidence for uncharted pinning points, The Cryosphere, 9, 1427-1443, https://doi.org/10.5194/tc-9-14272015, 2015.

Haran, T., Bohlander, J., Scambos, T., Painter, T., and Fahnestock, M.: MODIS Mosaic of Antarctica 2008-2009 (MOA2009) Image Map., Boulder, Colorado USA: National Snow and Ice Data Center., https://doi.org/10.7265/N5KP8037, 2014.

MacAyeal, D. R., Bindschadler, R. A., Shabtaie, S., Stephenson, S., and Bentley, C. R.: Force, mass, and energy budgets of the Crary Ice Rise complex, Antarctica, Journal of Glaciology, 33, 218-230, https://doi.org/10.3189/S0022143000008728, 1987.

Morlighem, M., Rignot, E., Seroussi, H., Larour, E., Ben Dhia, H., and Aubry, D.: Spatial patterns of basal drag inferred using control methods from a full-Stokes and simpler models for Pine Island Glacier, West Antarctica, Geophysical Research Letters, 37, L14 502, https://doi.org/10.1029/2010GL043853, 2010.

Still, H., Campbell, A., and Hulbe, C.: Mechanical analysis of pinning points in the Ross Ice Shelf, Antarctica, Annals of Glaciology, 60, 32-41, https://doi.org/10.1017/aog.2018.31, 2019.

Yu, H., Rignot, E., Seroussi, H., and Morlighem, M.: Retreat of Thwaites Glacier, West Antarctica, over the next 100 years using various ice flow models, ice shelt melt scenarios and basal friction laws, The Cryosphere, 12, 3861-3876, https://doi.org/10.5194/tc-12-3861-2018, 2018. 